\title{
A ExperiênCIA FranCESA ${ }^{(*)}$
}

Didier Truchet ${ }^{(\star \star)}$

\section{RESUMO}

Por sua localização e por seu estado de desenvolvimento, a França é um país que apresenta uma série de riscos sanitários e desafios para a administração sanitária. O arcabouço legal francês conta com uma ordenação jurídica sobre as situações em que há necessidade de se tomar medidas de restrição à liberdade, em benefício da proteção à saúde pública. Porém, assim como ocorre em outras nações, a sociedade francesa deparase sempre com a questão clássica de como determinar um nivel de restrição às liberdades que seja legítimo, em um cenário mundial dinâmico, que exige estratégias que variam em função das circunstâncias politicas, do desenvolvimento tecnológico e do próprio funcionamento da sociedade.

\section{Palavras-chave}

França; Legislação; Liberdade; Regulamento Sanitário Internacional; Riscos Sanitários.

\section{ABSTRACT}

Due to its localization and state of development, France is a country that presents a series of sanitary risks and challenges for the sanitary administration. The body of laws in France approaches several situations where it is necessary to take urgence measures which can affect civil liberties, in benefit

(*) Nota do editor: Trabalho apresentado durante o VII Seminário Internacional de Direito Sanitário realizado na Faculdade de Saúde Pública da Universidade de São Paulo. São Paulo. Setembro de 2006.

${ }^{(* *)}$ Professor da Universidade Panthéon-Assas (Paris II) e presidente da Associação Francesa do Direito à Saúde. E-mail: <truchetdidier@wanadoo.fr>. 
of the protection to the public health. However, as well as it occurs in other nations, the French society always comes across with the classic question of how to determine a level of restriction to the freedoms that is legitimate, in a dynamic world-wide scene, that demands strategies according to different politics scenes, technological development and the functioning of the society itself.

\section{Key words} tary Risks.

International Health Regulation; France; Legislation; Liberty; Sani-

\section{INTRODUÇÃO}

A exposição da França ao risco sanitário depende de diferentes aspectos.

Como um país europeu, a França apresenta um clima temperado. Porém, as mudanças climáticas e o aquecimento global podem expô-lo a doenças que não existiam até o presente momento. A nação também situase nas rotas das grandes migrações aviárias, que inclui o Norte da Europa e os continentes africano e asiático. Por essa razão, na primavera de 2006, foram encontrados dezenas de pássaros mortos em decorrência da gripe aviária, o que levou a tomada de medidas estritas para o fechamento das zonas afetadas.

Além disso, sendo uma nação bastante industrializada, recai sobre a França o peso dos riscos industriais e tecnológicos, como o que ocorreu em setembro de 2001, quando a explosão de uma usina química causou a morte de 30 pessoas e deixou um saldo de 2.500 feridos, na cidade de Toulouse.

A França também conta com um setor agrícola forte, o que deixa o país vulnerável a possiveis ameaças trazidas pela agricultura e criação de animais. A epizootia de encefalite espongiforme bovina demonstrou isto e, é por essa razão, que o cultivo de plantas genmeticamente modificadas é bastante debatido atualmente.

A população francesa também apresenta contrastes impressionantes, que a expõe a diversos riscos: a natalidade é uma das mais altas da Europa (um grande número de jovens) e, ao mesmo tempo, a população envelhece rapidamente (muitos idosos). A França conhece bem tanto as doenças relacionadas às nações ricas, como aquelas dos paises de origem de numerosos trabalhadores imigrantes acolhidos por ela. E, não se pode deixar de mencionar, os departamentos e territórios franceses ultramarinos, que fazem da França um país tropical, o qual se depara com uma epidemia 
causada por um mosquito quase desconhecido, o "chikungunya", que atingiu as Ilhas Reunião, em 2005. E, até mesmo, a dengue, doença endêmica na Polinésia Francesa.

Assim, existe uma larga gama de riscos sanitários que as autoridades francesas devem enfrentar.

E trata-se, sobretudo, de autoridades de Estado. As coletividades territoriais (comunas, departamentos e regiões) têm pouco poder e, em matéria sanitária, ele se concentra, mais e mais, nas mãos do Estado, mesmo que em outras áreas, a tendência geral seja a de delegar competências aos coletivos territoriais (movimento de descentralização).

Porém, o processo de decisão dentro do Estado está, ele mesmo, mais complexo e instável. Ao fim do século $X X$, o triste e célebre "escândalo do sangue contaminado" pelo virus da AIDS (HIV) abalou profundamente a administração do Estado e suscitou uma série de reformas que ainda não acabou. Um de seus traços mais marcantes é a multiplicação de órgãos decisórios e consultivos, que podem responder a uma necessidade de conhecimento e de democracia, mas que tornam mais lento o processo de decisão e enfraquecem a visibilidade do poder politico.

\section{I- O CONHECIMENTO DO RISCO SANITÁRIO}

Identificar o risco sanitário, avaliá-lo, analisar a gravidade, prever sua evolução são evidentemente tarefas indispensáveis para fazer frente às ameaças de maneira eficaz. Mas, sem dúvida, também são os aspectos mais difíceis de uma política sanitária.

\section{$A-O$ aparelho administrativo}

Avaliar o risco sanitário é a missão do Instituto Nacional de Vigilância Sanitária (INVS, sigla em francês), órgão do Estado, criado em 1998, que fica sob a tutela do Ministério da Saúde; porém, a instituição conta com bastante autonomia. O art. L. 1413-2, do Código de Saúde Pública (CSP, sigla em francês), prevê quatro objetivos para o Instituto:

1 - a vigilância e observação permanentes do estado de saúde da população;

2 - a vigilância sanitária;

3 - o alerta sanitário; e

4 - contribuir para a gestão de situações de crise sanitária.

O INVS não é um órgão de decisão, mas colabora com o poder público, fornecendo informações, estudos e mesmo proposições. Destinatário de um 
número considerável de informações, ele se apóia na Rede Nacional de Saúde Pública. Além disso, conta com dados dos serviços públicos, civis e militares, e pode solicitar informações para empresas públicas, privadas e de serviços funerários. Em caso de risco grave à saúde, "toda pessoa jurídica ou física é obrigada, por solicitação do INVS, a lhe comunicar toda a informação relativa a tais riscos" (art. L. 1413-5, CSP). Isso inclui até mesmo os laboratórios de análises biológicas. Quanto ao segredo médico, o Instituto o respeita em relação a terceiros.

O órgão mantém ligações estreitas com as agências francesas de Segurança Sanitária dos Produtos de Saúde, dos Alimentos, do Ambiente e do Trabalho e tem inúmeros instrumentos a sua disposição, tais como: sistemas de vigilância (farmacovigilância, hepato-vigilância, vigilância de materiais), "rede de sentinelas", centros de referência médica etc. Porém, o instrumento mais eficaz é também o mais antigo: a obrigação de relatar determinadas patologias às autoridades sanitárias. Segundo o art. L. 3113-1, do CSP, sejam "doenças que necessitam de uma intervenção urgente local, nacional e internacional", ou aquelas "sobre as quais é necessária a vigilância para a condução e avaliação de uma política de saúde pública". A declaração é feita pelo médico que diagnostica a moléstia, sem a identificação do doente. Esta relação aumenta a cada dia, sendo que o "chikungunya" e a dengue foram incluidos em abril de 2006. Atualmente, são relacionadas 30 patologias (art. D. 3113-6 e D. 3113-7, CSP).

É claro que as autoridades francesas estão em contato constante com seus homológos estrangeiros e com a Organização Mundial de Saúde (OMS). Sabemos que esta última é tributária de uma qualidade de informações que The passam os Estados-membros, embora, algumas nações sejam falhas neste ponto, seja porque lhes faltem meios de conhecer o estado sanitário de suas populações, seja porque elas relutem em transmitir informações alaramantes. Mas, no geral, o sistema todo funciona de maneira suficiente.

Assim, é impressionante ver como a divulgação, por parte da OMS, de dados inquietantes sobre o vírus $\mathrm{H} 5 \mathrm{~N} 1$, recolhidos em uma pequena cidade de uma ilha na Indonésia, pode provocar reuniões de crise em Paris e também em Brasilia, Londres, Washington ou Tóquio.

\section{B - O grau de conhecimento do risco}

Evidentemente, conhecer ou não o risco implica em cenários diferentes.

No caso de uma ameaça identificada, a vigilância fica relativamente mais tranqüila, pois as autoridades sabem o que procurar e dispõem de indicadores confiáveis. É o que acontece, por exemplo, com o vírus da gripe humana. Mas, não se deve imaginar que tudo será simples e acreditar que situações já conhecidas estarão sempre sob controle. Ocorre freqüentemente 
que os perigos sejam tardiamente avaliados. Foi preciso muito tempo para se saber os riscos do tabagismo, da exposição ao amianto ou mesmo do saturnismo, provocado pelo uso de encanamento doméstico em chumbo.

Outro caso de conhecimento tardio dos riscos, também relacionado ao saturnismo, foi a descoberta de que as aves que vivem em lagos, onde há muita atividade de caça, apresentaram a doença, devido à intoxicação por chumbo proveniente dos cartuchos depositados nos fundos destes lagos. Um perigo não apenas para as aves, mas também para os humanos que as consomem. Por este motivo, foi proibido o uso de lagos com menos de 30 metros, na França.

Lógico que é muito mais difícil controlar um risco desconhecido, como é o caso das doenças "emergentes", estas grandes e novas calamidades que o mundo não imaginava mais que pudessem surgir: SIDA, legionelose, SARS. Até agora, a França foi poupada pela última delas; mas foi duramente afetada pelas duas primeiras. Foram necessários anos de esforço para iniciar um sistema de vigilância eficaz que as incluiu na relação de doenças que devem, obrigatoriamente, ser informadas às autoridades sanitárias. Além disso, no caso da SIDA, os suspeitos de terem sido contaminados pelo HIV podem fazer testes de detecção de vírus anônimos e gratuitos.

No momento, é o vírus da gripe aviária que provoca preocupações, as quais repousam sobre uma hipótese que ninguém sabe se poderá se tornar real: a mutação do vírus que permitiria sua transmissão entre seres humanos. No senso estrito, é impossível rastrear a contaminação de homem para homem, uma vez que ela não existe. É preciso uma organização para se poder diagnosticá-la, com uma atenção particular nas zonas onde há mais possibilidade dessa contaminação surgir: aquelas onde a contaminação de homem por animal já ocorreu, o que não é o caso da França e de nenhum outro país Europeu, onde foram encontradas aves mortas.

$\mathrm{E}$, mesmo os sistemas de vigilância mais sofisticados podem apresentar falhas diante de um fenônemo natural. No verão de 2003, a França foi atingida por uma onda de calor que registrou temperaturas elevadissimas, durante o dia e à noite. Estima-se que ela tenha causado a morte de mais de 10 mil pessoas. Mesmo sendo um evento raro, a canícula é previsível e pode ser detectada pelos serviços metereológicos. Além disso, suas conseqüências sanitárias, principalmente sobre os indivíduos mais fragilizados, não são desconhecidas. Porém, passaram-se muitos dias até que as autoridades francesas compreendessem a gravidade excepcional da situação e colocassem em andamento medidas necessárias, como a divulgação de recomendações para a população se proteger dos efeitos do calor.

No caso, o INVS foi duramente criticado e o ministro da Saúde, demitido. As falhas aconteceram, em primeiro lugar, porque a administração da saúde não contava com indicadores apropriados para acompanhar as 
conseqüências da onda de calor. O fenônemo da canícula, em si, não é uma doença e também não constava nos atestados de óbito, como causa mortis. Acrescente-se a isto, o fato de não haver um cruzamento de dados - metereológicos, dos serviços de socorro ou do número de mortes - focado na canícula, que pudesse facilitar a identificação das conseqüências deste evento da natureza rapidamente. Foram os serviços hospitalares de urgência que deram o sinal de alerta, submersos em um afluxo de vítimas do calor excessivo.

Depois dessa infeliz experiência, o sistema de vigilância foi modificado e o "plano canícula" funcionou bem em julho de 2006, outro verão anormalmente quente.

\section{II - A ESCOLHA DAS MEDIDAS}

Uma vez que o risco sanitário é detectado, e conhecido na medida em que pode ser, as autoridades ficam responsáveis em definir as ações necessárias para evitar a ameaça, limitar ou pôr um fim as suas conseqüências.

\section{A-Os princípios}

Os principios jurídicos aplicáveis são, inicialmente, os clássicos da polícia administrativa. Na França, historicamente, eles são iniciados pelo Conselho de Estado (a mais alta jurisdição administrativa). Largamente compartilhados no mundo, eles se assemelham ao bom senso, dentro de uma sociedade democrática.

O primeiro é a eficácia da ação imaginada que deve ser útil, o que quer dizer, suscetivel de responder ao risco, e proporcional a ele. Deve-se, sempre, fazer um balanço entre os benefícios esperados e seus inconvenientes, em termos de restrições para as pessoas, de ameaças para a saúde pública, custos e outros interesses.

$\mathrm{Na}$ França, debateu-se se deveria ser obrigatória a realização de testes de detecção de vírus HIV, de maneira sistemática, junto aos profissionais de saúde - ou àqueles mais expostos a cortes e picadas - para evitar a contaminação dos pacientes. Os estudos mostraram uma conta desfavorável à obrigatoriedade, já que os casos conhecidos de contaminação eram muito raros; o interesse do teste, falível e, de outro lado, os testes pesariam sobre os trabalhadores, além do problema do custo das indenizações que teriam que ser pagas aos profissionais que não pudessem mais exercer suas atividades, por serem portadores do HIV. Este foi um resumo das discussões, ricas e detalhadas. Mas, a conclusão final é a de a obrigação dos testes era inoportuna. Melhor seria conscientizar os profissionais de saúde sobre medidas de prevenção para evitar a contaminação. 
Um segundo princípio implica em considerar a urgência das medidas tomadas. Como sempre, uma emergência pede ações rápidas e pode justificar atos radicais impostos pelas circunstâncias, os quais não seriam admitidos em outra ocasião. Opondo-se aqui ao princípio da precaução, uma urgência pode conduzir a ações das quais não se conhece todos os efeitos possiveis.

Um terceiro princípio afirma que as medidas, urgentes ou não, devem ser regularmente reavaliadas. As circunstâncias nas quais elas foram decididas, inicialmente, ou o conhecimento a seu respeito, podem evoluir, o risco se agravar, diminuir ou mudar de lugar. Os mecanismos de vigilância são destinados especialmente para este rastreamento, mas eles não são únicos. Assim para combater o vetor do paludismo, usou-se massivamente o DDT, até que a OMS recomendasse, há 30 anos, a renúncia a este método, em razão de seus efeitos sobre o ambiente. A evolução das técnicas de utilização permitiu que a substância voltasse a ser empregada.

Deve se acrescentar o princípio da precaução a esta relação? No Direito francês, o princípio da precaução diz respeito apenas ao ambiente (ele é mencionado no art. 4 da Carta do Meio Ambiente, adotada por lei constitucional de $1^{\circ}$ de março de 2005) e não à saúde. As jurisdições francesas não o aplicam no Direito à saúde, mas é preciso admitir que este cenário jurídico é bastante superficial.

De um lado, o princípio tende a se tornar um princípio geral do Direito comunitário da União Européia. Em um comunicado de 2 de fevereiro de 2000, a Comissão da Comunidade Européia afirmou que "O princípio da precaução não é definido por tratado, que não lhe indica a não ser em um caso para proteger o ambiente. Mas, na prática, seu campo de aplicação está cada vez mais amplo, particularmente quando uma avaliação científica objetiva preliminar indica que é razoável temer os efeitos potencialmente perigosos para o ambiente ou à saúde humana, animal ou vegetal, sendo eles incompatíveis com o nível elevado de proteção definido pela Comunidade".

De outro lado, ele é constantemente invocado pelos cidadãos, pela imprensa, associações e administração sanitária, seja para exigir medidas de proteção, seja para lhes justificar. Ele é assim desviado de seu sentido original, quando as autoridades públicas se apóiam nele para editar medidas (como, por exemplo, normas de segurança) que elas sabem ser difíceis de se aplicar. Na realidade, elas buscam, sobretudo, se eximir de suas próprias responsabilidades.

\section{B - O conteúdo das medidas}

O conteúdo das ações definidas para enfrentar os riscos sanitários é, obviamente, infinitamente variado. Pode-se distinguir as medidas permanentes daquelas de urgência. 
As primeiras são previstas pelas enormes legislação e regulamentação francesas. Algumas, sobretudo as que tratam da higiene do meio, têm raízes tão antigas, que remontam à Idade Média. A lei sobre higiene pública de 1902 é especialmente importante. Desde então, os textos evoluiram bastante e foram reunidos em um novo Código de Saúde Pública (ordenado em 15 de junho de 2000) que substituiu o precedente.

Este Código, que comporta milhares de artigos, é um instrumento de trabalho pesado para manipular, mas cômodo de utilizar (ao menos, para os especialistas), uma vez que reúne o conjunto de textos nacionais aplicáveis, em um esquema claro. Mas, a codificação de 2000 foi realizada em "direito contínuo", o que significa que os textos originais foram retomados, sem modificações (ou quase sem). Trata-se de um reagrupamento e não de uma nova fonte de legislação sanitária.

De maneira geral, ele é moderno e completo, mas sofre de falhas que afetam, atualmente, todo o conjunto da legislação francesa: verborragia, má redação, instabilidade, complexidade; em resumo, ininteligivel e sem a segurança jurídica que se esperaria. O Código de Saúde Pública distinguese de outras legislações francesas pela fraca influência que sofre do Direito comunitário da União Européia. O Direito à saúde é, em efeito, menos "europeizado" do que muitos outros ramos do Direito, na França.

Tratando agora das medidas de urgência, elas são aquelas decididas em resposta a uma situaçao de crise sanitária. Na presença de um risco conhecido, são em geral, previamente calculadas e basta colocá-las em andamento. Como aconteceu, por exemplo, quando da descoberta do caso de meningite cérebro-espinhal, em uma escola francesa, que deslanchou rapidamente uma reação eficaz das autoridades locais, com o apoio do Ministério, que havia sido imediatamente informado. Cada um sabe o que deve ser feito e o faz. Existe ainda uma série de planos destinados a enfrentar os principais cenários.

A situação é bem diferente quando se trata de um novo tipo de risco, que não pode ser antecipado, na qual é preciso improvisar, algo que não agrada a nenhuma administração pública.

Um exemplo significativo é a ameaça da SARS que provocou um verdadeiro pânico no Ministério da Saúde, alimentado, notadamente, pela pressão das companhias aéreas que queriam orientações sobre como proteger suas tripulações e passageiros. E, parece que este pânico foi sentido em todo o mundo.

$\mathrm{Na}$ França, imaginaram-se as soluções mais extremas, tais como o confinamento domiciliar, sobre vigilância policial, dos passageiros sãos, mas recém-chegados de zonas infestadas ou a proibição feita aos franceses contaminados pela SARS no estrangeiro de voltarem para o pais. Estas soluções não foram colocadas em andamento, primeiro porque a epidemia parece ter regredido, depois porque lhes faltava base legal. 
Com efeito, percebeu-se que no arsenal legislativo francês, faltava uma regra compacta e sumária para reagir a uma ameaça de pandemia mundial, tanto que acreditou-se terem voltado os tempos das grandes pestes. llusões de um país rico e orgulhoso de suas conquistas tecnológicas, mas surpreendido por uma situação tão brutal e fora do alcance de seus recursos terapêuticos. Na verdade, não havia a necessidade de uma regra legislativa específica, uma vez que o Direito francês já comporta técnicas utilizáveis em casos semelhantes. Mas, o Ministério da Saúde, cuja competência jurídica é falivel, as ignorou ou se negou a Ihes fazer confiança.

É por essa razão que, em 9 de outubro de 2004, introduziu-se no Código de Saúde Pública, uma regra compacta e sumária que, acreditavase, the faltava. O art. L. 3110-1, alínea 1, dispõe, notadamente, que: "Em caso de ameaça grave que necessite de medidas de urgência, especialmente um risco de epidemia, o ministro da Saúde pode, por decisão fundamentada, dentro do interesse da saúde pública, prescrever ações proporcionais aos riscos correntes e apropriadas às circunstâncias, para prevenir e limitar as conseqüências das possiveis ameaças à saúde da população".

Até o momento, felizmente, não houve necessidade de aplicar esse texto em resposta à SARS. Mas, ele oferece uma base legal para se iniciar um plano governamental de prevenção e combate a uma "pandemia gripal" se, por infelicidade, a França for afetada por uma epidemia de gripe aviária, transmitida de ser humano para ser humano.

\section{III - RISCOS SANITÁRIOS E LIBERDADE}

Aqui está a clássica questão e complexa de como conciliar liberdade, do indivíduo e também do Estado, com medidas necessárias para os riscos sanitários. Antes de mais nada, convém destacar que os franceses dispõem de três liberdades fundamentais:

1 - a liberdade de se tratar, que cada um pode efetivamente exercer, porque os tratamentos são largamente realizados pela seguridade social ou pela "cobertura universal da doença";

2 - a liberdade de não se tratar, recusando os cuidados médicos ou abandonando a instituição hospitalar. Os tratamentos são obrigatórios apenas em casos de doenças mentais que possam trazer perigo para os próprios doentes ou para outras pessoas;

3 - a liberdade de escolha médica ou de estabelecimento de saúde, uma vez que a responsabilidade da seguridade social é a mesma em todos os lugares.

Claro que, a realidade não é tão perfeita: cada uma destas liberdades tem limites de direito ou de fato, que tendem a se agravar pelo déficit da 
cobertura social. Mas, apesar de tudo, pode-se dizer que, em nenhum outro país no mundo, a garantia dessas três liberdades é tão forte, não apenas em princípio, mas também de fato, como na França.

\section{A - Liberdade dos cidadãos}

A forma de prevenção aos riscos sanitários que mais respeita a liberdade dos cidadãos é a comunicação que não faz parte, exatamente, da tradição administrativa francesa, historicamente mais voltada para comandar do que para se explicar. Mas, ela desenvolveu-se bastante e hoje é muito praticada. A comunicação foi a estratégia escolhida (principalmente para estimular o uso de preservativos) para o combate à SIDA e teve bons resultados, em conjunto com outras iniciativas como exames gratuitos ou o programa de troca de seringas, destinados aos usuários de drogas.

O uso da comunicação corresponde bem ao estágio atual da sociedade: os franceses gostam de se saberem livres para correr riscos contra sua própria saúde, caso desejem; contudo, querem tomar suas decisões com conhecimento de causa. Não se admite que uma ameaça seja ocultada e a sociedade francesa, hoje em dia, está pronta a questionar judicialmente a responsabilidade do Estado ou de empresas privadas por falhas de comunicação.

Assim, recorre-se freqüentemente às recomendações. Por exemplo, como está acontecendo no combate à obesidade (alguns preferiram que os doces e refrigerantes fossem retirados das máquinas distribuidoras de guloseimas das escolas; outros tentaram mesmo uma distribuição de maçãs para os alunos; mas o fracasso foi completo). A recomendação é o único meio à disposição das autoridades, quando a lei não permite restrições, uma vez que no Direito francês, a liberdade é o princípio e sua violação, uma exceção que é definida, normalmente, em lei. É assim que, como é legalmente impossivel (salvo raras exceções relacionadas com processos e condenações penais) proibir que um detentor de passaporte francês saia do território nacional, para um destino de sua escolha, o Ministério dos Assuntos Estrangeiros publica recomendações dirigidas aos viajantes que desejem se arriscar em uma zona de perigo (sanitário, ou mais freqüentemente de segurança), aconselhando-os a não visitarem estas áreas ou a se precaverem contra as ameaças.

A escolha mais delicada se situa em um nivel mais elevado de pressão, entre a restrição (obrigação ou interdição) imposta por uma lei e a recomendação. É o que acontece atualmente com a vacinação.

A lei francesa impõe vacinações obrigatórias, seja para crianças (difteria, tétano, poliomielite, paratifóide e, na prática, tuberculose), seja para 
certos profissionais expostos a riscos particulares as suas atividades. Em razão da oposição de certos pais e médicos, a taxa de cobertura de vacinação da população francesa é pior do que a dos países vizinhos, onde as vacinas são apenas recomendadas. Algumas pessoas concluem que a obrigatoriedade da vacina é, não apenas ineficaz, como contraprodutiva e que ela viola de tal forma a liberdade individual que deveria ser abolida. De outro lado, existem os que afirmam que em um país onde o espírito cívico é menos presente, passar de obrigação para recomendação provocaria uma queda da cobertura de vacinação e a um risco de novas epidemias.

As estratégias jamais são definitivas e variam em função das circunstâncias, do conhecimento adquirido, da opinião pública ou de mudanças de ordem política. Assim, a luta contra o tabagismo, que não existia, começou por meio da comunicação, depois passou para medidas restritivas, cada vez mais pesadas, acrescentando-se sanções penais. Inversamente, o combate ao alcoolismo não envolve mais tratamento obrigatório, mas apenas recomendações e repressão penal para certos casos (como por exemplo, a ingestão de bebida alcoólica em vias públicas ou ao volante). Mas, existem possibilidades de injunções de tratamentos dirigidos aos toxicômanos ou delinqüentes sexuais, com fortes garantias procedimentais em seu interesse.

O panorama é então contrastante, é mutável. E não pode ser de outra forma, em um campo tão sensivel, onde a tensão permanente entre liberdade e segurança é particularmente forte e onde as atenções dos cidadãos são contraditórias.

Em seu conjunto, a legislação francesa é liberal, de tal forma que a administração sanitária, às vezes, fica impedida de agir. Há alguns anos, uma epidemia de tuberculose, em uma residência de trabalhadores imigrantes, em um bairro de Paris, representou uma série de dificuldades para os administradores. O respeito escrupuloso à lei, que não permite a imposição de exames ou tratamentos, comprometeria o combate à epidemia. Estava-se, com efeito, na presença de pessoas sem identificação correta, em geral, em situação irregular, que eram desconfiadas e apresentavam grande mobilidade. Foi preciso muita pedagogia e diplomacia para tratar com as lideranças dessa comunidade, mas também usou-se a pressão, por meio de ameaças para que todos fizessem os exames e, se necessário, os tratamentos ambulatoriais ou hospitalares. Esta prática era de uma legalidade incerta; mas necessária e eficaz. Em contrapartida, a administração comprometeu-se a não expulsar os imigrantes clandestinos que aceitassem passar pelo exame e pelos tratamentos.

Hoje, em uma situação hipotética idêntica, o novo art. L. 3110-1, do Código de Saúde Pública, já mencionado, ofereceria os recursos necessários à administração que the faltou na época: porém, seriam eles mais eficazes? 


\section{B - Liberdade da França e comércio internacional}

Como todos os países, a França mantém uma série de compromissos internacionais, os quais, por sua vez, constituem-se em ajuda e incômodo, quando se trata de prevenir um risco sanitário com origem no exterior.

Como membro da OMS, a França deve observar o Regulamento Sanitário Internacional (RSI). O atual regulamento tem um campo de aplicação restrito e um conteúdo preciso: o que é suficiente para a resolução de problemas. Além do mais, o RSI raramente é invocado nos tribunais franceses. Continuará assim, mesmo com o novo Regulamento que deverá entrar em vigor em julho de 2007, mais ambicioso?

As dificuldades surgem quando a Regulação não é aplicável, sendo que o caso mais freqüente é: a França pode se opor à livre entrada, em seu território, de produtos e mercadorias que o país acredita apresentar algum risco sanitário para sua população?

Os grandes instrumentos internacionais relativos à liberdade de comércio tratam desse assunto. Assim, o art. 2.1 do Acordo sobre a Aplicação de Medidas Sanitárias e Fitossanitárias, anexo ao Acordo de Marraquesh que instituiu a Organização Mundial de Comércio (OMC), em 15 de abril de 1994, estipula que: "Os Estados-membros têm o direito de definir medidas sanitárias e fitossanitárias necesárias à proteção da saúde e da vida das pessoas e animais, ou à preservação dos vegetais, com a condição de que essas medidas sejam compativeis com as disposições do presente Acordo". $\mathrm{O}$ art. 30 do Tratado da Comunidade Européia estipula que: "As disposições dos arts. 28 e 29 [que proíbem restrições quantitativas entre os Estados-membros] não são obstáculo às interdições ou restrições de importação, exportação ou de trânsito, justificadas por razões de [...] proteção à saúde e a vida das pessoas e animais, ou à preservação dos vegetais [...]. De qualquer maneira, essas interdições ou restrições não devem constituir nem uma forma de discirminação arbitrária, nem uma restrição disfarçada no comércio entre os Estados-membros".

Sabemos que a exceção da saúde pública é freqüentemente utilizada pelos países, como uma forma de protecionismo disfarçada que resulta em uma abundância de contenciosos internacionais, em particular, nas instâncias de regulação de conflitos da OMC ("rodadas") ou na Corte de Justiça da Comunidade Européia (CJCE) . Assim, nos anos 90, quando uma epizootia de encefalite espongiforme bovina atacou o rebanho da Grã-Bretanha e ameaçou toda a Europa, a França proibiu a importação da carne britânica. Nesse momento, o país não cometia nenhum ato ilícito, pois o embargo foi autorizado pela "Comissão de Bruxelas". Mas, quando este embargo foi suspenso, com a avaliação de que o perigo havia passado, o governo francês manteve a proibição, claro que, impulsionado pelos criadores franceses que se beneficiaram comercialmente, protegidos da concorrência inglesa. Processada pela Comissão, a França foi condenada pela CJCE (caso C 
1/100, 13 de dezembro de 2001) e suspendeu seu embargo. Note-se que 0 país apelou, em vão, ao princípio da precaução.

Mais significativo é o caso das plantas geneticamente modificadas. A França havia acordado em autorizar seu cultivo por um periodo de três anos. Então, o Greenpeace francês pediu ao Conselho de Estado do país a anulação desse acordo. Depois de consultar o CJCE, o Conselho não o anulou ... e, ainda por cima, aumentou o prazo da autorização de três, para cinco anos, seguindo a regulamentação da Comunidade Européia. Assim, o recurso do Greenpeace teve um efeito surpreendente de, não apenas não cancelar o acordo, como de confirmar as autorizações por um prazo maior do inicial, que estava sendo questionado. Isso demonstra que as regras da União Européia relativas aos organismos geneticamente modificados privaram os Estados-membros do essencial de sua capacidade de decisão.

\section{CONCLUSÃO}

O caso da França não é especial; ele se parece, em efeito, ao de seus vizinhos. Mas, a semelhança não é completa, porque em matéria de saúde, as diferenças nacionais continuam fortes, mesmo dentro da União Européia. Confirma-se que, em uma sociedade democrática "do Norte", aberta para o mundo exterior, a detecção e a prevenção do risco sanitário envolve relações complexas e mutáveis com a liberdade.

Contrariamente ao que se passa em países "do Sul", na França, o problema principal não é o acesso às medidas de prevenção, aos tratamentos e medicamentos, devidamente garantido. Trata-se, sobretudo, em determinar o nível de restrição que é legítimo de se impor, em nome da saúde pública.

\section{VERSÃO EM FRANCÊS}

\section{L'eXPerienCe FranÇaise}

Didier Truchet ${ }^{(*)}$

L'exposition de la France au risque sanitaire dépend de sa situation.

La France métropolitaine est un pays européen, donc soumis à un climat tempéré. Mais l'évolution du climat et son réchauffement pourraient

(*) Président de l'Association Française de Droit de la Santé, Professeur à I'Université PanthéonAssas (Paris II). 
l'exposer à des maladies qui n'y étaient pas présentes jusqu'à présent. Elle est située sur les routes des grandes migrations aviaires entre le Nord de l'Europe, l'Afrique et l'Asie: des dizaines d'oiseaux morts de la grippe aviaire (H5N1) ont été trouvés sur son sol au printemps 2006 et suscité de strictes mesures de fermeture des zones concernées.

Elle est un pays fortement industrialisé, sur lequel pèsent de lourds risques industriels et technologiques, qui se réalisent parfois: en septembre 2001, une explosion dans une usine chimique a provoqué la mort de 30 personnes et en a blessé plus de 2500 dans la ville de Toulouse.

La France est aussi un pays d'agriculture puissante. Elle est donc très concernée par les risques que l'élevage et la culture font peser sur la santé humaine. L'épizootie d'encéphalite spongiforme bovine l'a montré. De très vifs débats entourent aujourd'hui la culture de plantes génétiquement modifiées.

La population française offre de saisissants contraste qui l'exposent à des risques très divers: la natalité y est l'une des plus élevées d'Europe (beaucoup de jeunes), mais elle vieillit très rapidement (beaucoup de personnes âgées). Elle connaît aussi bien les pathologies attachées aux pays riches que celles des nombreux travailleurs migrants qu'elle accueille.

II ne faut pas oublier que ses départements et territoires d'outre-mer font aussi de la France un pays tropical: la dengue est endémique en Polynésie française; en 2005, un épidémie, causée par une sorte de moustique quasiment inconnu, le chikungunya, a durement frappé la Réunion.

C'est donc à une large gamme de risques sanitaires que les autorités publiques doivent faire face.

II s'agit surtout des autorités de l'État. Les collectivités territoriales (communes, départements et régions) ont très peu de pouvoirs: en matière sanitaire, ceux-ci sont de plus en plus concentrés dans les mains de l'État, alors que, pour toutes les autres matière, la tendance générale est de confier de plus en plus de compétences aux collectivités territoriales (mouvement de décentralisation).

Mais le processus de décision au sein de l'État est lui-même de plus en plus complexe et instable. A la fin du $X X^{\text {éme }}$ siècle, le tristement célèbre "scandale du sang contaminé" par le SIDA a profondément ébranlé l'administration d'Etat et suscité une série de réformes qui ne sont pas achevées. L'un des traits les plus frappants est la multiplication des organes décisionnels ou consultatifs, qui peut répondre à un besoin de connaissance et de démocratie, mais ralentit le processus de décision et affaiblit la visibilité du pouvoir politique. 


\section{I - LA CONNAISSANCE DU RISQUE}

Identifier le risque sanitaire, le mesurer, en apprécier la gravité, en prévoir l'évolution sont évidemment des tâches indispensables si l'on veut faire efficacement face à la menace. Mais c'est sans doute l'aspect le plus difficile d'une politique sanitaire.

\section{A - L'appareil administratif}

Mesurer le risque sanitaire est la mission de l'Institut national de veille sanitaire (INVS) qui a été créé en 1998. II s'agit d'un établissement public de l'État placé sous la tutelle du ministre de la santé, mais qui, en réalité, agit de manière assez indépendante de ce dernier.

L'article L. 1413-2 du code de la santé publique (CSP) lui donne quatre types de missions:

1 - la surveillance et l'observation permanentes de l'état de santé de

la population;

2 - la veille et la vigilance sanitaires;

3 - l'alerte sanitaire;

4 - une contribution à la gestion des situations de crise sanitaire.

L'INVS n'est pas un organe de décision, mais il contribue à la décision des pouvoirs publics par les informations qu'il porte en permanence à leur connaissance, les études qu'il mène et les propositions qu'il leur fait.

II est destinataire d'un nombre considérable d'informations. II s'appuie sur le réseau national de santé publique. L'ensemble des services publics civils et militaires lui transmettent les informations nécessaires à sa mission. II est habilité à en demander d'autres aux entreprises publiques et privées et aux entreprises de pompes funèbres. En cas de risques graves pour la santé publique, "toute personne physique et toute personne morale est tenue, à la demande de l'INVS, de lui communiquer toute information en sa possession relative à de tels risques" (art. L. 1413-5 CSP). II en va de même des laboratoires de biologie médicale. Le secret médical ne lui est pas opposable, mais l'Institut doit évidemment le respecter envers les tiers.

L'institut entretient des liens étroits avec l'Agence française de sécurité sanitaire des produits de santé, l'Agence française de sécurité sanitaire des aliments et l'Agence française de sécurité sanitaire de l'environnement et du travail.

Les instruments à sa disposition sont nombreux et divers: systèmes de vigilance (pharmaco-vigilance, hépato-vigilance, matériaux-vigilance...), "réseaux sentinelle", centres médicaux de référence... 
L'instrument le plus efficace est aussi le plus ancien: les maladies qui doivent faire l'objet d'une déclaration obligatoire à l'autorité sanitaire. Selon l'art. L. 3113-1 CSP, ce sont soit des "maladies qui nécessitent une intervention urgente locale, nationale et internationale", soit des "maladies dont la surveillance est nécessaire à la conduite et à l'évaluation de la politique de santé publique". La déclaration est faite par le médecin qui diagnostique la maladie, sans que le malade puisse être identifié.

Le liste comporte ne cesse d'augmenter, le chikungunya et la dengue y ayant été ajoutés en avril 2006. Elle comporte actuellement trente maladies (art. D. 3113-6 et D. 3113-7 CSP).

Bien entendu, les autorités françaises sont en liaison constante avec leurs homologues étrangères et avec l'Organisation mondiale de la santé. On sait que cette dernière est tributaire de la qualité des informations que lui fournissent les États membres et que certains d'entre eux sont défaillants sur ce point, soit qu'il manque de moyens pour connaître l'état sanitaire de leur population, soit qu'ils répugnent à transmettre des informations alarmantes. Mais de manière générale, le système fonctionne assez bien.

Il est par exemple frappant de voir comment la transmission par l'OMS de données inquiétantes recueillies sur le virus $\mathrm{H} 5 \mathrm{~N} 1$ dans un petit village d'une île indonésienne suscite, dans les heures qui suivent, des réunions de crise à Paris, mais certainement aussi à Brasilia, Londres, Washington ou Tokyo!

\section{$B$ - Le degré de connaissance du risque}

La situation n'est évidemment pas la même selon que le risque est bien ou mal connu.

Dans le cas d'un risque identifié et bien connu, la surveillance est relativement aisée, car les autorités sanitaires savent ce qu'elles cherchent et disposent d'indicateurs fiables. On le voit par exemple avec le virus de la grippe humaine.

Mais il ne faut pas croire que tout serait simple et penser que des situations anciennes seraient toujours sous contrôle. II arrive fréquemment que l'on n'en mesure la dangerosité que tardivement. II a fallu, ainsi, beaucoup de temps pour mesurer les dangers du tabagisme, ceux de l'exposition à l'amiante ou les risques de saturnisme infantile que font courir les canalisations d'eau en plomb.

On a progressivement découvert que les canards vivant dans des étangs où ils sont abondamment chassés étaient atteints de saturnisme en raison de l'absorption des plombs des cartouches tombés au fond de l'eau, ce qui est dangereux non seulement pour eux, mais pour les hommes qui les 
mangent après les avoir tués. C'est pourquoi l'usage à moins de trente mètres d'un étang de cartouches contenant du plomb vient d'être interdit en France.

II est évidemment beaucoup plus difficile de surveiller un risque encore très mal connu.

C'est le cas des maladies dites "émergentes", ces grands fléaux nouveaux que le monde n'imaginait pas voir surgir: SIDA, légionellose, SRAS. La France a été épargnée, pour l'instant, par le dernier d'entre eux, mais durement touchée par les deux premiers. II a fallu des années d'effort pour mettre en place un système de veille efficace : ils sont tous deux aujourd'hui des maladies à déclaration obligatoire, le SIDA faisant en outre l'objet d'un dépistage facultatif, anonyme et gratuit.

En ce moment, c'est le virus de la grippe aviaire qui suscite l'inquiétude, mais cette inquiétude repose sur une hypothèse dont nul ne sait si elle se produira: une mutation du virus permettant sa transmission de l'homme à l'homme. Au sens strict, il est impossible de suivre la contamination interhumaine, puisqu'elle n'existe pas. II faut s'organiser pour pouvoir la diagnostiquer si elle se produit, avec une vigilance particulière dans les zones où elle paraît le plus susceptible d'apparaître: celles où une contamination de l'homme par l'animal s'est déjà produite, ce qui n'est pas le cas de la France, non plus que d'aucun des pays d'Europe où des oiseaux morts ont été trouvés (à ma connaissance du moins).

Je voudrais évoquer une autre expérience, qui montre que, même très sophistiqués, les systèmes de veille et d'alerte peuvent avoir de graves défaillances devant un phénomène pourtant très naturel. Dans l'été 2003, la France a connu durablement des températures diurnes et - surtout-nocturnes - exceptionnellement élevées: on estime qu'elles ont provoqué le décès de plus de 10000 personnes. Même rare, la canicule n'est pas un évènement totalement imprévisible, elle est mesurée par les services de la météorologie, et ses conséquences sanitaires, sur les sujets fragiles en particulier, ne sont pas inconnues!

Or il a fallu plusieurs jours pour que les autorités sanitaires françaises comprennent la gravité exceptionnelle de la situation et puissent prendre les mesures et donner les conseils nécessaires pour que la population se protège des effets de la chaleur. L'INVS a été très critiqué et le ministre de la santé à dû démissionner. Leur défaillance tenait en premier lieu à ce que la canicule n'étant ni une maladie, ni une cause de décès indiquée sur les certificats de décès, l'administration de la santé n'avait pas d'indicateur propre pour en suivre les effets; en second lieu, qu'elle n'était pas immédiatement destinataire de données dont le croisement aurait peut-être permis d'identifier le phénomène plus rapidement: données météorologiques, statistiques d'intervention des services de secours, chiffres des pompes funèbres ... C'est finalement les services hospitaliers d'urgence, submergés par un afflux de victimes de la canicule, qui ont donné l'alerte. 
Depuis lors, le système de veille a été modifié pour tenir compte de cette expérience malheureuse: le "plan canicule" a d'ailleurs bien fonctionné en juillet 2006 qui a été, à nouveau, anormalement chaud.

\section{II - LE CHOIX DES MESURES}

Une fois le risque sanitaire détecté, et connu autant qu'il peut l'être, il incombe aux autorités de l'État de prendre les mesures nécessaires pour éviter la menace, y mettre fin ou en limiter les conséquences.

\section{A - Les principes}

Les principes juridiques applicables sont d'abord ceux, classiques, de la police administrative. En France, ils ont été historiquement dégagés par le Conseil d'État (la plus haute juridiction administrative). Très largement partagés dans le monde, ils semblent de bon sens dans une société démocratique.

Le premier est celui de l'efficacité de la mesure envisagée. Elle doit être utile, c'est-à-dire susceptible de répondre au risque. Mais elle doit aussi être proportionnée à ce dernier. II faut toujours établir un bilan entre ses avantages attendus et ses inconvénients en termes de contrainte pour les personnes, de risques pour la santé publique ou pour d'autres intérêts généraux et de coûts.

On s'est demandé en France si un dépistage systématique du SIDA chez les professionnels de santé - ou chez les plus exposés aux coupures et piqûres parmi eux - ne devrait pas être rendu obligatoire pour éviter qu'ils contaminent leurs patients. Les études ont montré un bilan défavorable: les cas connus de contamination étant très rares, l'intérêt du dépistage était faible; il aurait en revanche lourdement pesé sur les professionnels et aurait coûté très cher s'il avait fallu les indemniser de l'impossibilité d'exercer leur art en cas de résultat positif. Je résume ici des débats qui ont été riches et nuancés, mais la conclusion a été qu'une obligation de dépistage imposée par la loi était inopportune: mieux valait rappeler les mesures de précaution et les recommandations envers les praticiens concernés, et faire appel à leur sens des responsabilités.

Un deuxième principe impose de prendre en considération l'urgence des mesures. Comme toujours l'urgence impose d'agir vite. Elle peut justifier des mesures radicales, imposées par les circonstances, qui ne seraient pas admises en son absence. S'opposant ici au principe de précaution, elle peut conduire à des mesures dont on ne mesure pas encore tous les effets possibles. 
Un troisième principe veut que les mesures prises, en urgence ou non, soient régulièrement réévaluées. Les circonstances dans lesquelles elles ont été prises initialement ou les connaissances à leur sujet ont pu évoluer, le risque s'aggraver, se réduire ou se déplacer.

Les mécanismes de vigilance sont spécialement destinés à ce suivi, mais ils ne sont pas les seuls. Ainsi pour lutter contre le vecteur du paludisme, on a massivement utilisé le DDT, avant que l'OMS recommande, il y a trente ans, d'y renoncer en raison de ses effets sur l'environnement ; l'évolution de la situation et des techniques d'utilisation vient de la conduire à le recommander à nouveau.

Faut-il ajouter à ces trois principes le principe de précaution? En droit français, le principe de précaution ne concerne que l'environnement (il est d'ailleurs mentionné à l'article 4 de la Charte de l'environnement adoptée par la loi constitutionnelle du 1er mars 2005) et pas la santé; les juridictions françaises ne l'appliquent pas en droit de la santé. Mais il faut bien admettre que cette présentation juridique est assez artificielle.

D'une part, le principe tend à devenir un principe général du droit communautaire. Dans une communication du 2 février 2000, la Commission des communautés européennes écrivait: "Le principe de précaution n'est pas défini par le traité, qui ne le prescrit qu'une seule fois - pour protéger l'environnement. Mais, dans la pratique, son champ d'application est beaucoup plus vaste, plus particulièrement lorsqu'une évaluation scientifique objective et préliminaire indique qu'il est raisonnable de craindre que les effets potentiellement dangereux pour l'environnement ou la santé humaine, animale ou végétale soient incompatibles avec le niveau élevé de protection choisi par la Communauté".

D'autre part, il est constamment invoqué par les citoyens, la Presse, les associations et l'administration sanitaire elle-même, soit pour exiger des mesures de protection, soit pour les justifier.

II se trouve à mon sens dévoyé lorsque des autorités publiques s'appuient sur lui pour édicter des mesures (par exemple, des normes de sécurité) qu'elles savent très difficiles à appliquer; en réalité, elles cherchent surtout à mettre à couvert leur propre responsabilité!

\section{$B$ - Le contenu des mesures}

Le contenu des mesures prises pour faire face aux risques sanitaires est bien sûr infiniment varié. On peut distinguer les mesures permanentes et les mesures d'urgence.

Les premières sont prévues par les énormes législation et réglementation françaises. Certaines, qui concernent surtout l'hygiène des milieux, 
ont des racines très anciennes, remontant au Moyen Age. La loi sur l'hygiène publique de 1902 a été une date importante. Depuis lors, ces textes se sont beaucoup développés. Ils ont été réunis dans un nouveau code de la santé publique (ordonnance du 15 juin 2000) qui s'est substitué au précédent devenu très incomplet.

Ce code, qui comporte des milliers d'articles, est un instrument de travail lourd à manipuler mais commode à utiliser (du moins pour les spécialistes), puisqu'il réunit l'ensemble des textes nationaux applicables, selon un plan clair. Mais la codification de 2000 a été faite "à droit constant", c'est-àdire en reprenant sans les modifier (ou presque) les textes existants: il s'agit d'un regroupement, non d'une refonte de la législation sanitaire.

De manière générale, celle-ci est moderne et complète. Mais elle souffre des défauts qui affectent aujourd'hui l'ensemble de la législation française: bavarde, mal rédigée, très instable, complexe, bref peu intelligible et n'offrant, de ce fait, pas toute la sécurité juridique que l'on serait en droit d'attendre d'elle. Elle se distingue d'autres ensembles législatifs français par la faible influence qu'exerce sur elle le droit communautaire: le droit de la santé est en effet moins "communautarisé" que beaucoup d'autres branches du droit français.

Les mesures d'urgence sont prises lorsqu'il s'agit de répondre à une situation de crise sanitaire.

En présence d'un risque connu, elles sont été en général prévues à l'avance et il suffit de les mettre en œuvre. Par exemple, un cas de méningite cérébrospinale dans une école française déclenche très rapidement une réaction efficace des autorités locales, avec l'appui du ministère immédiatement informé. Chacun sait ce qu'il doit faire et le fait. II existe ainsi toute une série de plans destinés à faire face aux principaux scénarios.

Le situation est très différente lorsque la crise est d'un type nouveau que l'on n' a pas pu anticiper. II faut alors improviser, ce qu'aucune administration n'aime faire!

La menace de SRAS en a fourni un exemple significatif. II a suscité une véritable panique au ministère de la santé, alimentée par celle notamment des transporteurs aériens qui l'interrogeaient sur la conduite à tenir et les précautions à prendre pour protéger leurs équipages et leurs passagers. Pour autant que je le sache, cette panique a été ressentie un peu partout dans le monde.

En France, on a pu imaginer les solutions les plus extrêmes, telles que le confinement à leur domicile, sous la surveillance de la police, de passagers sains mais rentrant de zones infestées ou l'interdiction faite à des français touchés par le SRAS à l'étranger de revenir en France ... 
Ces solutions n'ont pas été mises en œuvre, d'abord parce que l'épidémie a régressé rapidement, ensuite parce qu'elles manquaient de base légale.

On s'est en effet aperçu que dans notre arsenal législatif subtile et diversifié, manquait une règle massive et sommaire pour réagir à une menace de pandémie mondiale, tant on croyait révolu le temps des grandes pestes! Illusions d'un pays riche et fier de ses techniques, mais pris au dépourvu par une situation aussi brutale et échappant à ses ressources thérapeutiques. A vrai dire, il n'était pas besoin d'une règle législative spécifique, puisque le droit français comportait déjà des techniques utilisables en pareil cas. Mais le ministère de la santé, dont la compétence juridique est faible, les ignorait ou répugnait à leur faire confiance.

C'est pourquoi une loi du 9 août 2004 a introduit dans le code de la santé la règle massive et sommaire qui, croyait-on, y manquait. L'article $L$. 3110-1, alinéa 1, dispose notamment: "En cas de menace grave appelant des mesures d'urgence, notamment en cas de menace d'épidémie, le ministre chargé de la santé peut, par arrêté motivé, prescrire dans l'intérêt de la santé publique toute mesure proportionnée aux risques courus et appropriée aux circonstances de temps et de lieu afin de prévenir et de limiter les conséquences des menaces possibles sur la santé de la population".

Pour l'instant, il n'a, fort heureusement, pas été nécessaire d'appliquer ce texte au cas du SRAS. Mais il offrirait une base légale pour la mise en œuvre du plan gouvernemental de prévention et de lutte "Pandémie grippale" si, par malheur la France était touchée par une épidémie de grippe aviaire devenue transmissible d'homme à homme.

\section{III - RISQUES SANITAIRES ET LIBERTÉ}

On trouve ici la question classique mais difficile de la conciliation de la liberté, celle des personnes mais aussi celle de l'État, avec les mesures rendues nécessaires par les risques sanitaires.

II convient d'abord de souligner que les français disposent de trois libertés fondamentales:

1 - la liberté de se soigner, que chacun peut exercer effectivement parce que les soins sont largement pris en charge par l'assurance maladie ou la "couverture maladie universelle";

2 - le liberté de ne pas se soigner, en refusant les soins ou en quittant l'établissement où ils sont délivrés. Les soins obligatoires ne concernent plus que les malades mentaux dangereux pour eux-mêmes ou pour autrui qui refusent de se faire soigner;

3 - le libre choix de son médecin ou de son établissement de soins, puisque la prise en charge par l'assurance maladie est la même partout. 
La situation n'est pas bien sûr pas parfaite: chacune de ces libertés connaît des limites de droit ou de fait, qui tendent à s'aggraver du fait du grave déficit de l'assurance maladie. Néanmoins, on peut affirmer qu'aucun autre pays au monde n'assure de manière aussi large ces trois libertés, non seulement en principe mais en réalité, que la France.

\section{A - La liberté des citoyens}

La forme de prévention des risques sanitaires la plus respectueuse de la liberté des citoyens est celle de l'information. Elle correspondait assez peu aux traditions de l'administration française, historiquement plus portée vers le commandement que vers l'explication. Mais elle s'est beaucoup développée et est aujourd'hui très pratiquée. C'est celle qui a été choisie (notamment en faveur de l'usage du préservatif) avec un certain succès pour lutter contre le SIDA, avec d'autres mesures incitatives comme le dépistage gratuit ou le programme d'échange de seringues pour les toxicomanes.

L'information correspond bien à l'état actuel de la société: les français estiment de plus en plus qu'ils doivent être libres de courir les risques pour leur propre santé qu'ils souhaitent prendre, mais veulent le faire en connaissance de cause. Ils n'admettent pas qu'un risque leur soir caché et sont aujourd'hui prompts à mettre en cause la responsabilité de l'État ou des entreprises pour défaut d'information.

On recourt aussi beaucoup aux recommandations. Par exemple, on commence à le faire pour lutter contre l'obésité (outre le fait que les sucreries et les boissons les plus sucrées ont été retirées des distributeurs de friandises dans les établissements scolaires; on a tenté aussi une distribution de pommes aux élèves, mais l'échec a été complet!). La recommandation est le seul moyen à la disposition des autorités lorsque la loi ne permet pas la contrainte, puisque, en droit français la liberté est le principe, et sa restriction une exception qui repose normalement sur une loi. C'est ainsi que, comme il est légalement impossible (sauf rares exceptions liées à la procédure et aux condamnations pénales) d'empêcher le détenteur d'un passeport français de quitter la territoire national pour la destination de son choix, le ministère des affaires étrangères publie des recommandations envers les voyageurs qui souhaitent se rendre dans une zone à risques (risque sanitaires, ou, plus souvent, sécuritaires), leur conseillant de ne pas s'y rendre ou de prendre de strictes précautions.

Le choix le plus délicat se situe à un degré plus élevé de pression, entre la contrainte (obligation ou interdiction) imposée par une loi et la recommandation. On en a un exemple avec le débat récurrent sur les vaccinations.

La loi française impose des vaccinations obligatoires, soit pour tous les jeunes enfants (diphtérie, tétanos, poliomyélite, para-typhoïde et, en pratique, 
tuberculose), soit pour certains travailleurs exposés à des risques particuliers. Or du fait de l'opposition de certains parents et de certains médecins, le taux de couverture vaccinale de la population est moins bon que dans des pays voisins où ces vaccinations sont simplement recommandées! Certains en concluent que l'obligation vaccinale est non seulement inefficace, mais contre-productive et qu'elle porte à la liberté individuelle une atteinte si gráve qu'elle devrait être abrogée. D'autres répondent que dans un pays où l'esprit civique est moins répandu que dans les pays considérés, passer de l'obligation à la recommandation conduirait à un effondrement de la couverture vaccinale et à un risque nouveau d'épidémie ....

Les choix ne sont jamais définitifs et varient en fonction des circonstances, des connaissances, des attentes de l'opinion publique et ou des changements de majorité politique. La lutte contre le tabagisme est ainsi passée du néant à l'information, puis à une contrainte de plus en plus lourde, assortie de sanctions pénales. Inversement, la lutte contre l'alcoolisme ne comporte plus de mesures de soins obligatoires, mais seulement des recommandations et une répression pénale de certaines formes d'ivresse (sur la voie publique, et surtout, au volant d'une voiture). Mais il existe des possibilités d'injonctions de soins envers les toxicomanes ou les délinquants sexuels, avec de fortes garanties procédurales pour les intéressés.

Le panorama est donc contrasté et mouvant. II ne peut en être autrement dans une matière aussi sensible où la tension permanente entre la liberté et la sécurité est particulièrement forte et où les attentes des citoyens sont contradictoires.

Dans l'ensemble, il est libéral au point que l'administration sanitaire est parfois démunie pour agir. II y a quelques années, une épidémie de tuberculose dans une résidence pour travailleurs immigrés dans le onzième arrondissement de Paris lui a posé bien des difficultés. Le respect scrupuleux de la loi, qui ne permet pas d'imposer un dépistage ou des soins, compromettait la lutte contre l'épidémie: on était en effet en présence de personnes mal identifiées, méfiantes, très mobiles et souvent en situation irrégulière. II a fallu user de beaucoup de pédagogie et de diplomatie avec les chefs de cette communauté, mais aussi de pressions, voire de menaces pour obtenir qu'elles se prêtent toutes à un dépistage et, si nécessaire à des soins ambulatoires ou hospitaliers: ces pratiques étaient d'une légalité incertaine, mais elles étaient nécessaires et ont été efficaces. En contrepartie, l'administration avait pris l'engagement de ne pas expulser les immigrés clandestins qui acceptaient le dépistage et les soins.

Aujourd'hui, dans une hypothèse identique, le nouvel article L. 3110-1 CSP, précité, donnerait à l'administration les moyens de contrainte qui lui avaient manqué à l'époque: seraient-ils, pour autant, plus efficaces? 


\section{B - Liberté de la France et commerce international}

Comme tous les Etats, la France est tenue par des engagements internationaux. Ils constituent à la fois une aide et une gêne pour elle, lorsqu'il s'agit de prévenir un risque sanitaire importé.

Comme membre de l'Organisation mondiale de la santé, elle doit observer le règlement sanitaire international (RSI). L'actuel RSI a un champ d'application étroit et un contenu précis: son application ne pose donc guère de problème. Il est d'ailleurs très rarement invoqué devant les tribunaux français. En ira-t-il de même avec le nouveau RSI qui doit entrer en vigueur en juillet 2007, et qui est plus ambitieux?

Les difficultés surgissent lorsque le RSI n'est pas applicable, ce qui est le cas le plus fréquent: la France peut-elle s'opposer à la libre entrée sur son territoire des produits et marchandises qu'elle estime présenter un risque sanitaire pour sa population?

Les grands instruments internationaux relatifs à la liberté du commerce auxquels elle est partie le prévoient. Ainsi l'article 2.1 de l'Accord sur l'application des mesures sanitaires et phytosanitaires annexé à l'Accord de Marrakech instituant l'Organisation mondiale du commerce - OMC (15 avril 1994), stipule: "Les Membres ont le droit de prendre les mesures sanitaires et phytosanitaires qui sont nécessaires à la protection de la santé et de la vie des personnes et des animaux ou à la préservation des végétaux à condition que ces mesures en soient pas incompatibles avec les dispositions du présent Accord". L'article 30 du Traité instituant la Communauté européenne stipule: "Les dispositions des articles 28 et 29 [qui interdisent les restrictions quantitatives entre les États membres] ne font pas obstacle aux interdictions ou restrictions d'importation, d'exportation ou de transit justifiées par des raisons de [...] de protection de la santé et de la vie des personnes et des animaux ou de préservation des végétaux [...]. Toutefois, ces interdictions ou restrictions ne doivent constituer ni un moyen de discrimination arbitraire, ni une restriction déguisée dans le commerce entre les États membres".

On sait que cette exception de santé publique est souvent utilisée par les États comme un moyen de protectionnisme déguisé. Elle suscite un abondant contentieux international, en particulier devant l'instance de règlement des conflits de l'OMC ("panels") ou devant la Cour de Justice des Communautés Européennes (CJCE).

'Lorsque, dans les années 1990, un épizootie d'encéphalite spongiforme bovine est apparue en Grande Bretagne et a menacé toute l'Europe, la France a interdit l'importation de viande britannique. Elle ne faisait là rien d'illicite, puisque cet embargo était conforme aux décisions de la "Commission de Bruxelles". Mais, lorsque cette dernière, estimant le danger passé, a levé cet embargo, le gouvernement français l'a maintenu. II y était bien sûr 
poussé par les agriculteurs français qui trouvaient tout avantage à être protégés de la concurrence anglaise. Poursuivie par la Commission, la France a été condamnée par la CJCE (affaire C. 1/100, 13 décembre 2001) et a levé l'embargo: on notera en particulier qu'elle a invoqué en vain devant la Cour le principe de précaution.

Plus significative peut-être est l'affaire des plantes génétiquement modifiées. La France avait accordée des autorisations pour les cultiver pendant trois ans. L'Association Greenpeace France a demandé au Conseil d'État leur annulation. Après avoir consulté la CJCE, le Conseil d'État ne les a annulées ... qu'en tant que leur durée était de trois ans au lieu des cinq ans imposés par la réglementation communautaire: ainsi, le recours de Greenpeace a eu cet effet surprenant que les autorisations non seulement n'ont pas disparu, mais ont été en réalité confirmées pour une durée supérieure à ce qui était prévu! Cela tient à ce que des règles communautaires relatives aux organismes génétiquement modifiés (OGM) ont privé les États membres de l'essentiel de leur capacité de décision. Cela n'est pas sans portée en France où une partie de l'opinion conteste, par la violence parfois, la culture des OGM.

\section{CONCLUSION}

Le cas de la France est banal: il ressemble en effet à celui de ses voisins. Mais la ressemblance n'est pas entière, car, en matière de santé, les différences nationales restent fortes, même au sein de l'Union européenne.

Il confirme que, dans une démocratie "du Nord" ouverte sur le monde extérieur, la détection et la prévention du risque sanitaire entretient des relations complexes et mouvantes avec la liberté.

Contrairement à ce qui se passe souvent dans les pays "du Sud", le problème principal n'est pas l'accès aux mesures de prévention, aux soins et aux médicaments: il est correctement assuré en France. II tient surtout à la détermination du degré de contrainte qu'il est légitime d'imposer au nom de la santé publique. 